\section{Transform your payroll}

Rather than ask why choose specialist provider Wagemate to manage your payroll, the question should be 'Why not?'

Your payroll will be accurate, on time and compliant. As legislation makes payroll more complex, Wagemate will allow you to get on with growing your business.

Wagemate is about simplicity, combining expertise with the best use of technology, such as its secure ePayslips portal.

Interested? Contact payroll specialists Wagemate on 03330102102 or email info@wagemate.com.

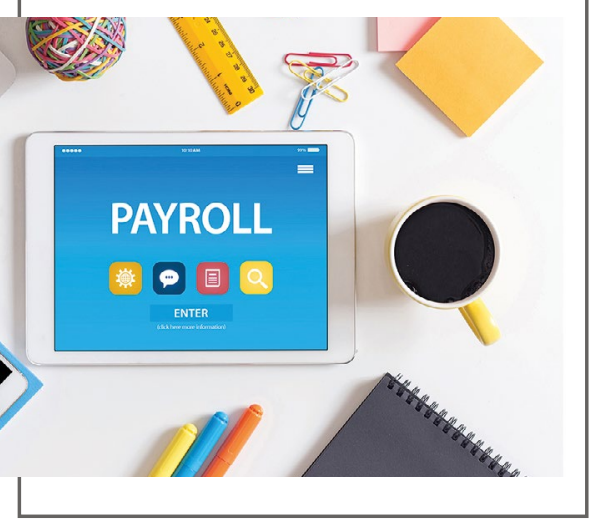

\section{Perfectly paired}

Pair your Carl Zeiss EyeMag dental loupes with the powerful EyeMag Light II to achieve perfect clarity as you work.

The EyeMag Light II delivers coaxial, daylight-quality illumination that is evenly distributed across the entire treatment site for a clear, unaltered view of tiny details and structures, with minimal shadow formation. It comes complete with two rechargeable battery packs that each offer up to 8 hours of operation for a virtually interruption-free workflow.

With a swing-in image filter that prevents premature curing of composite materials, the EyeMag Light II is a must-have solution for your restorative armamentarium.

For more information please Nuview on 01453 872266, email info@nuviewltd.com, visit www.nuview.co.uk or 'like' Nuview on Facebook.

\title{
Go to market with us
}

Finding the right buyer for your dental practice is important for a smooth transaction. After all, you will have invested a great deal of time and capitol into making your business a success, so it's essential it's left in the right hands.

Dental Elite can provide professional support throughout your practice sale, including when you go to market. The friendly team will work with you to agree a prospectus and prepare the necessary paperwork, before promoting the sale to its extensive database of active buyers. In turn, you maximise your chances of securing a buyer that aligns with your values and vision for the future of the business.

For more information contact Dental Elite on 01788 545900, info@dentalelite. co.uk or visit www.dentalelite.co.uk.

\section{Think about your future}

Looking to break into implant dentistry with training and support you can trust? Ucer Education's Postgraduate Certificate (PGCert) in Implant Dentistry (EduQual Level 7) is a highly established course that offers training in the latest, evidence-based techniques.

The multi-system programme is delivered by an esteemed faculty, led by Specialist Oral Surgeon, Professor Cemal Ucer. You will gain
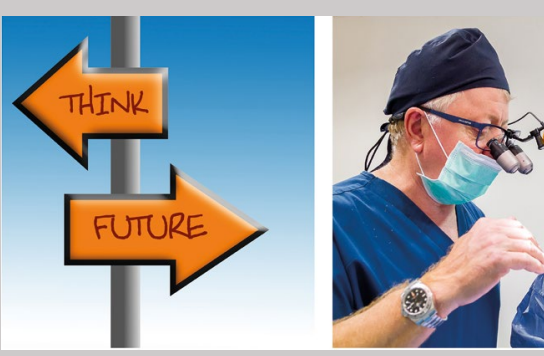

an outstanding foundation in all aspects of modern implant dentistry, from the basics of patient assessment and treatment planning to multiple advanced surgical techniques. Training covers both theory and practical aspects and assessments, ensuring that you have the knowledge and confidence you need to take a successful step into the world of dental implants.

For more information on the PG Cert in Implant Dentistry from Ucer Education supported by Geistlich, Megagen, Neoss, TRI Implants and General Medical - visit www.ucer. education, call Prof Ucer on 07767645331 or email ucer@oral-implants.com.

\section{The learning you've missed}

All IAS Academy training courses are being delivered in the most efficient and COVID-safe environments possible to give you total peace of mind while you learn from industry-leading clinicians. Courses are designed to strictly adhere to relevant Government guidelines, prioritising the safety of all in attendance. They were already providing small group sizes for intimate learning opportunities, but all potential extra measures have now been added too.

This means you can confidently get back to the in-person learning you have missed over the past year. Whether you're interested in developing your ortho-restorative skills, improving your clinical photography or advancing your orthodontic capabilities with fixed appliances, IAS Academy can help.

With courses available in Crawley, London, Birmingham, Surrey, Newcastle and Cambridge, there's sure to be one near you.

For more information on IAS Academy membership and upcoming training courses, please visit www.iasortho.com, email courses@iasortho.com or call 01932 336470 (Press 1).

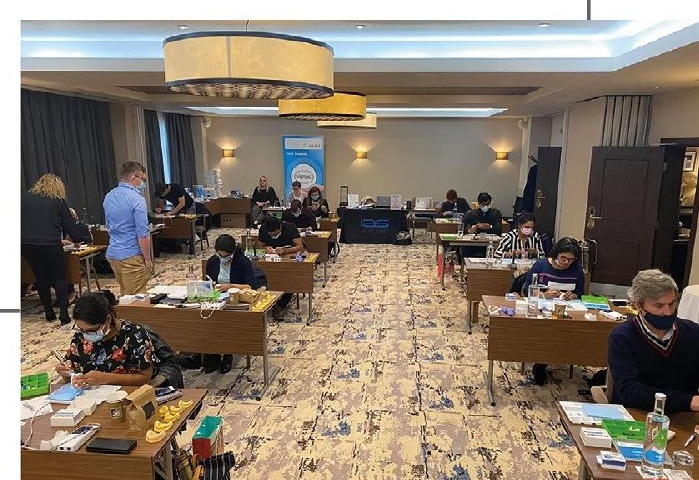

